\title{
VINHOS EM PORTUGAL ANTES DAS REGIOES DEMARCADAS
}

\author{
Aurélio de Oliveira \\ Universidade do Porto e ISMAI
}

Resumo: Com o presente estudo pretende-se verificar e circum-escrever no tempo as raízes das "modernas" delimitações das grandes regiões vinhateiras portuguesas, ordenadas a partir do Poder Central, indagando das razões históricas e económicas dessas mesmas delimitações (ora precoce, ora tardiamente ordenadas).

A História dos Vinhos (ou de determinado vinho) é hoje uma componente importante na estratégia quer da sua venda, quer das regiões produtoras que também se tornaram destinos turísticos, só por si, escolhidos por uma fatia bem considerável de quem viaja. Os vinhos têm a sua história, e essa história (mais ou menos longa mais ou menos recuada) ajuda, sem dúvida, a sua venda a sua promoção e o seu consumo).

Palavras-Chave: Regiões vinhateiras; regulamentação; história do vinho e da vinha.

\section{Abstract: Wines in Portugal before the demarcated regions}

The present study aims to verify and bound in time the rootsof "modern" out lines of thegreat portuguese wine regions, commanded by the Central Power, enquiring the historical and economicreason sof these same boundaries (som etimesearly, some timeslatelycommanded).

The History of Wines is now an important component in the strategy either of the sale, or of the producing regions that became touristd estinations, in themselves chosen by a very considerable share of travelers. Wines have their history, and that history (a longer or shorter, going further back into the past or not) undoubtedly helps their sale,their promotion, and their consumption).

Keywords: wine producing regions; regulation; history of wine and vineyard

Resumen: Los vinos en Portugal antes de las regiones demarcadas

Este estudio tiene como objetivo verificar y circunscribir en el tiempo las raíces de las "modernas" delimitaciones de las grandes regiones vinateras portuguesas, ordenadas desde el poder central, así como indagar las razones históricas y económicas de esas delimitaciones (a veces temprana, a veces tardiamente ordenadas).

La historia de los vinos (o de determinado vino) es actualmente un elemento importante de la estrategia ya sea de su venta, ya de las regiones productoras que también se han convertido en destinos turísticos, elegidos por una parte muy considerable de quienes viajan. Los vinos 
tienen su historia, y esa historia (más o menos larga o breve), sin duda ayuda a su venta, promoción y consumo.

Palabras clave: regiones vinateras, regulación, historia del vino y de los viñedos

\section{VENHAMOS AO CASO NACIONAL.}

Todos nós conhecemos a intervenção de Pombal, relativamente ao Douro em 1756, criando a Companha dos Vinhos e criando a primeira região demarcada, ordenando e regulando administrativamente a Região Vinhateira do Douro, estabelecendo as fronteiras geográficas da sua produção e comércio de vinhos dessa região. Ao analisarmos historicamente essa intervenção verifica-se que ela é na realidade tardia, isto é, confrontada com uma realidade anteriormente construída. Todavia a primeira a ser decretada por um poder central, tanto no quadro nacional como, até, no quadro europeu. Tardia em termos da presença e construção de uma realidade. Na verdade já "naturalmente" demarcada desde tempos bem anteriores. Entenda-se naturalmente como fruto de uma realidade "natural" construída nos tempos anteriores mas também definida e demarcada, protegida e delimitada por outro tipo de poderes - o poder local- neste caso a partir do Município do Potro. Paradoxalmente um poder local e agindo desde fora da região vinhateira. Um caso notável, aliás, uma cidade vinhateira construída fora da região vinhateira, fora das áreas de produção. Ora, o critério que tem sido seguido na criação e erecção destas realidades isto é, identificação das regiões vinhateiras demarcadas, tem sido (é) o acto administrativo emanado do poder Central. Foi (é) esse faco político que tem determinado por vários quadros europeus e também nacional, a consagração e a "idade" das actuais regiões vinhateiras.

No caso nacional e em relação às actuais regiões, são, como dizemos, intervenções tardias relativamente ao que, de modo natural, se havia já construído em certas áreas geográficas.Todavia e de facto, determinação pioneira relativamente ao que depois se verificou ou foi verificando por várias regiões da Europa. Isto é, estas são praticamente todas posteriores às demarcações pombalinas. Em suma, o caso da demarcação do Douro é uma realidade tardia relativamente ao que, de modo próprio e natural, desde muito tempo antes se tinha construído (protegido e defendido) por outro tipo de poder - pelo poder local. Precoce, no contexto genérico da realidade europeia. No caso dos outros vinhos e logo da região dos Vinhos Verdes, muito mais tardia ainda. O acto administrativo da demarcação da região dos vinhos Verdes data 1908 (promulgação do diploma. Os trabalhos, todos concluídos em 1907 pelo Governo de João Franco). Ora, também aqui, isto é, no seu circuito, alguma área mais restrita se tinha construído e delimitado e solidificado desde muito cedo e igualmente protegida por várias determinações e medidas do poder local. É o caso do Monção. 
Ora, é em busca dessas delimitações e construções "naturais", fora dos actos administrativos dimanados do poder central que afinal, legal e formalmente as institucionaliza as cria, que pretendemos hoje sucintamente partir. Assim, o que nós pretendemos é es-

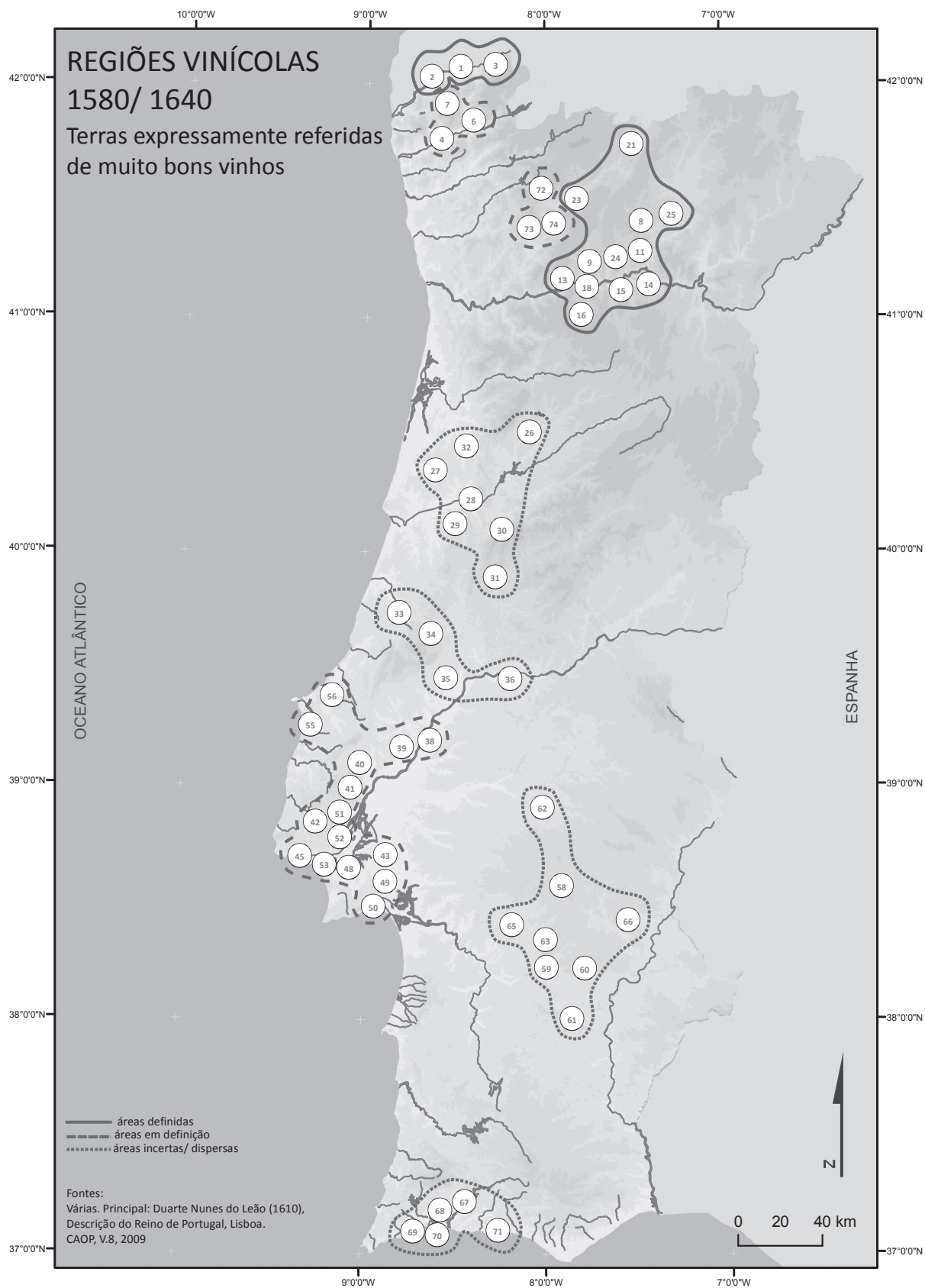


tudar e seguir esse processo e essa realidade até ao acto formal que as legalizou - enfim - que as criou. Essa busca e caracterização de um processo e de uma génese que me parece importante. Relativamente ás regiões administrativamente criadas por esse poder central, realmente tardias à sua construção natural, tomar em consideração esse processo histórico bem como a importância da acção de outro tipo de poderes - o poder local - isto é, de determinado ou determinados municípios (visto que não tivemos nunca poderes regionais alargados definidores de realidades económicas e sociais específicas). As demarcações dos inícios o Seculo XX, procuraram ir em direcção a estas últimas realidades, criando regiões em grande parte coincidentes com as grandes divisões tradicionais do território. Mas em breve se questionou tal critério, ou se verificou ser demasiado genérico acabando por dar origem às várias sub-regiões, em que todas elas se partiram, mesmo para o Douro em que a homogeneidade parece mais evidente. Hoje como se sabe, subdividido em Baixo Corgo, Cima Corgo, e Douro Superior.

O cultivo da vinha é uma realidade em todo o território nacional nos tempos anteriormente aqui delimitados, tendo passado, é verdade, por alguns momentos de mais notória expansão como, também, contracções circunstanciais. Todavia, em termos de longa duração, sempre em crescimento constante. Razões várias. Umas, ordem natural e histórica, outras até, de ordem sociológica mas, sobretudo, de ordem económica. Passemo-las todas, tendo-as, embora, em consideração.

$\mathrm{O}$ acontecimento maior e mais decisivo deste incremento dos vinhos, desencadeia-se com o processo das Descobertas, isto é, com o alargamento dos tratos, clientes e mercados e com o crescimento de um enorme mercado interno - Lisboa - e um enorme cliente - a Coroa.

Uma procura crescente e sequente. Um crescimento numa primeira fase muito determinadas pela proximidade geográfica dos maiores centros do trato e depois, à medida que se foram apaladando os gostos e preferências ou as exigências dos clientes, tradicionais ou de outros que iam chegando ou aos quais iam sendo "servidos", as preferências e o gosto dos bebedores! Os estrangeiros, a troco dos panos, do pescado e do pão foram-se envolvendo com alguns vinhos nacionais. Assim, corriam com os vinhos bons negócios em Lisboa, nos princípios do Século XVI. Sempre, inevitavelmente, animando ou consolidando as áreas melhor posicionadas para os tratos sejam internos sejam, sobretudo, os que mais se articulavam com o exterior.

Ao abrir o século XVI e na sequência de uma realidade mais marcada ainda nos tempos anteriores, em termos de uma visão panorâmica global, as principais áreas vinhateiras estão localizadas preferentemente no Sul. Lisboa era já a principal cabeça dos tratos e de toda a articulação com os novos espaços atlânticos. E o grosso da clientela era aí que afluía. As principais escápulas de extracção posicionavam-se em áreas muito próximas ou de muito fácil articulação com a capital. Algumas zonas do Algarve, (tão buscado pelas suas frutas entre as quais a própria uva), continuavam a atrair muitos clientes de fora e mesmo mercadores nacionais, até de pontos bem afastados como Viana do Lima que, desde tempos bem anteriores aí os iam carregar para levar para fora. Em toda esta clientela estrangeira a preferência ia, então, como continuou a ir por muito tempo, para os vinhos 
"finos e leves". Os do Algarve respondiam em particular a estes quesitos. Estes vinhos ganharam, assim, inegavelmente, alguma fama e proveito.

A expansão dos vinhedos é uma realidade muito importante já durante toda a primeira metade do Século XVI. De modo algum é sustentável a afirmação de que só pelos finais do Século XVI é que os vinhos passam a ter interesse no contexto da agricultura nacional. Já por 1523 ficaria bem expressa essa importância já adquirida ao referir-se a muita quantidade de vinhos por todas as Comarcas do reino, e a sua muita afluência ao grande mercado que era Lisboa. Por 1535 a expansão é de tal ordem que assistiremos, mesmo, à primeira intervenção no sentido de limitar e suster tão grande expansão (Coisa - que saibamos - nunca referida até hoje). Muita aristocracia de dinheiro e muita nobreza andava, então, metida nos plantios e, evidentemente também, nos tratos (Oliveira, 2004; Oliveira, 2011)

Essas áreas e esses vinhos vão sempre em crescendo, em termos de movimentos longos, por toda acentúria e consolidam-se, definitivamente, nos primeiros tempos de Seiscentos isto é, durante a primeira metade do Século.

Desde aqui poderão precisar-se já algumas terras de bons vinhos. A geografia económica geral do Reino, de Duarte Nunes Leão, permite uma primeira visualização dessa implantação nos finais de Quinhentos - princípios de Seiscentos. Advirta-se, porém, como é natural (e Nunes de Leão o sublinha também), que se lavrava vinho por todos os lugares do Reino. Todavia, a referência expressa, a algumas terras mostrará já um primeiro debuxo das zonas vinhateiras ou, então, de maior nome -“alguns dos que tem grande nome"- como sublinha.

Divisaremos assim, três grandes zonas, ainda que dispersas, quiçá muito indefinidas:

Uma zona mediterrânica ou meridional, com especial relevo para o Algarve: Alvor, Vila Nova de Portimão e Lagos.

No Alentejo os da zona de Évora com os de Pêra Manca a sobressair em fama e substância". Por aqui pelos finais de Quinhentos, se anota a abundância de muitos e bons vinhos. Mas neste conjunto, há ainda os de Beja (brancos): os de Alvito, Viana, Vila de Frades e Alcáçovas.

No circuito de Lisboa: Alcochete e Caparica (de muita fama em Flandres e Alemanha para onde se exportavam com muita regularidade e de grande fama entre as capas altas destes lugares). Ainda no termo ou proximidade de Lisboa, os da Estremadura: Loures, Charneca, Oeiras, Unhos e Camarate e os "muito estremados" de Torres Novas.

Na zona centro: Leiria, Ourém. Os de Cantanhede, os da Lousã e Figueiró (que, por isso, se chama dos Vinhos). Diz ainda: "são infinitos os de Santarém, Alenquer e Torres Vedras de que se faz a maior exportação. (Mas Gil Vicente (e a Parda), não ia(m) lá muito com os de Santarém e de Óbidos)! Refere ainda que nas Beiras há também muito bons vinhos (sem citar em específico qualquer um). Cremos que poderemos apontar os da região de Coimbra, em cujos arredores por 1550 se produzem excelentes vinhos "tão bons como os de Falerno ou Metima" e onde viajantes, pouco depois, se surpreendem com as "muitas e boas vinhas). Por Anadia (Dão) - outras fontes referem como zona muita vinha e também de bons vinhos. 
Na parte Norte do reino nomeiam-se apenas os de Cima-Douro, que saem geralmente todos com o nome de Vinhos de Lamego. (Todavia, de modo algum ali se circunscrevem pois há muitos e excelentes vinhos na margem Norte (talvez mesmo, os melhores), de que se faz exportação para os mercados do Reino e para o exterior (Vide Vinhos de Cima-Douro, cit. e Capítulos para a História do Douro). Nestes ditos de Lamego, andam metidos outros, hoje incluídos na demarcação dos Verdes, que também se exportavam e que até aqui têm sido sempre tomados como maduros, isto é, empolando a exportação dos "lamegos" ou maduros de Lamego (Oliveira). Finalmente, os de Monção de que se faz também exportação para os mercados internos, desde o Minho a Lisboa. Sempre em crescendo também desde inícios, e com saída já assegurada para o exterior sendo em particular de citar o interesse de flamengos, franceses e ingleses, por estes vinhos. Os ingleses os preferirão durante muito tempo aos de Cima Douro.

\section{CONSTRUÇÕES. PRECOCES DELIMITAÇÕES. DOIS EXEMPLOS.}

Temos chamado a atenção para a importância do período filipino, tanto do ponto de vista económico como social particularmente face ao quadro que se foi desenhando a partir, genericamente da primeira década de Seiscentos.

Tendo passado por um primeiro período de contracção, o surto económico do tecido agrícola (e não só) é uma realidade e um facto a partir de determinada altura, não sendo mais possível manter, sob este ponto de vista, a ideia de uma crise generalizada e profunda durante os sessenta anos deste domínio. De modo algum é possível meter tudo no mesmo saco da decadência levando-o às costas para todo o lado que nos viremos. De um modo geral, a partir dos primeiros dez ou doze anos de Seiscentos a recuperação é visível atingindo, embora de modo diferente, o tecido geográfico nacional. Mais visível nos centros urbanos, mais tocadas as regiões ribeirinhas. Um crescimento demográfico inegável em todo o conjunto até 1640-41 chegando algumas localidades a duplicar a sua população relativamente à contagem de 1527. E sabe-se o que isso significa em termos económicos para este período. O testemunho directo de um contemporâneo (a partir da Mitra e Cabido de Braga) referente à última parte deste período, parece lapidar: um crescimento notável das rendas como se fora por milagre: "parece que milagrosamente se multiplicavam" - refere este testemunho. Postergado o milagre como em Ourique, tem que se aceitar outras causas: a realidade do crescimento económico que, ao ritmo normal do pulsar cíclico, se irá prolongar até 1640-41 (Oliveira, 1998).

Ora, uma das realidades marcantes e das mais importantes e significativas, concretizou-se e materializou-se, no sector primário, em torno da expansão e consolidação da vinha, da produção e do trato com os vinhos. Uma realidade tão grande que os níveis de produção atingidos já durante a década de Vinte e dos tempos posteriores levarão muito tempo a serem ultrapassados.

Desde o Algarve, à região de Lisboa a vários panos das Beiras, ao Douro e ao Entre Douro e Minho. Num processo generalizado, poderemos tomar como diapasão o que dis- 
se um estrangeiro (ainda a que especificamente se referindo ao circuito da capital "vinhas por todo o lado" (Lisk, 1878: 250). Curioso mas sintomático desta expansão é o facto de que para as terras de Castelo Branco, por exemplo, se recomendar, em 1616, que se não plantem mais vinhedos! Tal era a azáfama do plantio e a expansão dos vinhos (Silva, 1616: 209).

Até os críticos mais radicais que afirmaram a inelutável decadência nacional, em toda linha, tiveram que constatar a importância e o surto vinícola verificados. O que, na realidade, não deixa de constituir um contra-senso, sabido o que o segmento vinhateiro, por estes tempos, significa e representa em todo o conjunto do sector primário (Labrousse, 1944; Vilar,1962: 370-371).

O alargamento e consolidação dos vinhedos durante Administração Filipina é, de facto, um dado importante e de muito relevo. Áreas já tradicionalmente vinhateiras ou não (mais aquelas que estas), viram a expansão da cultura e o sucessivo apreço dos seus vinhos.

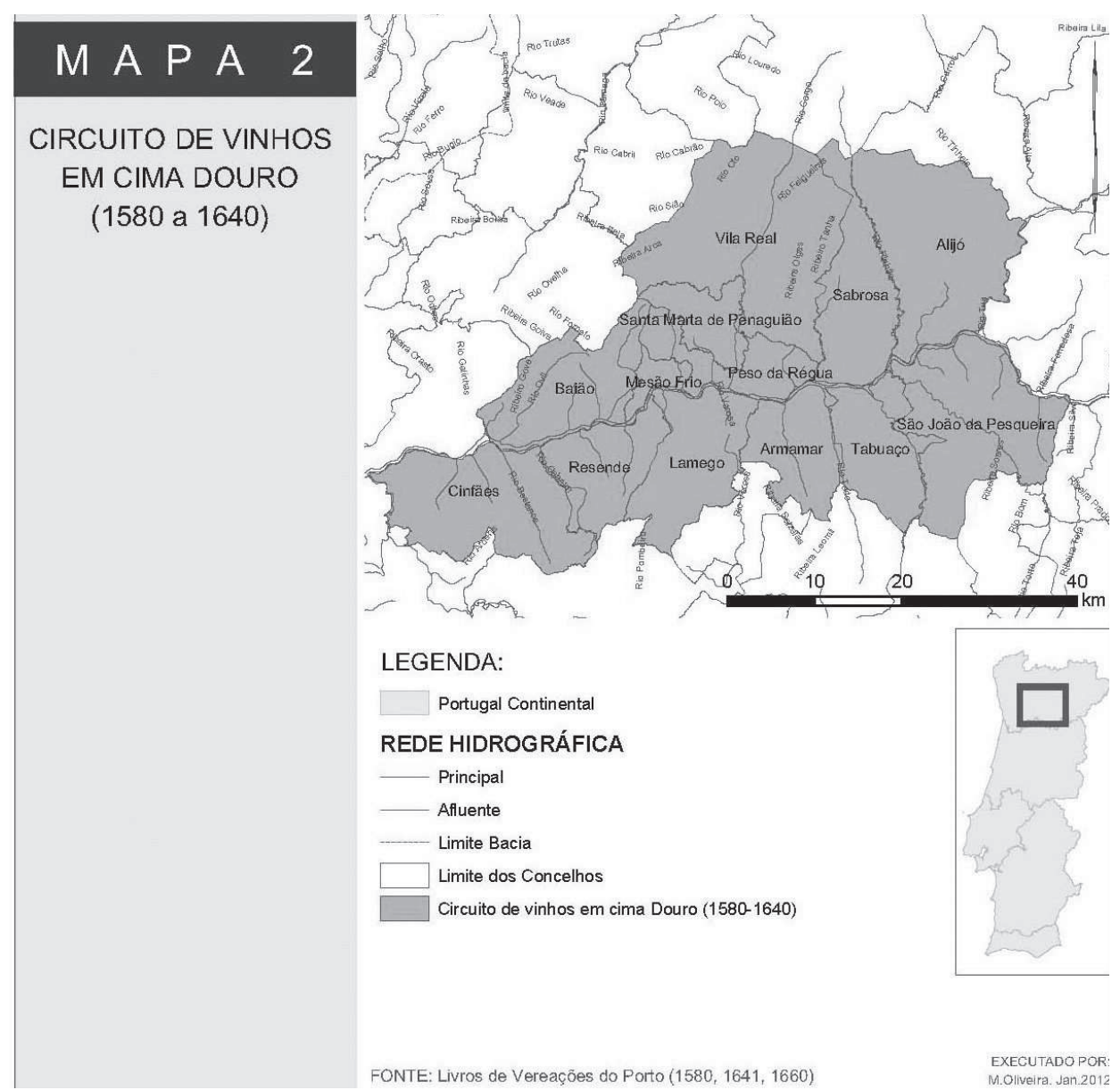


Ao fim desta Administração Filipina os vinhos estão em expansão delimitando-se (naturalmente) as áreas dos mais fadados. Por todo o lado: do Minho a Trás-os Montes e Beiras; da Estremadura ao Alentejo e Algarve.

É neste contexto que vemos surgir áreas especialmente protegidas, quase delimitadas, que defendem os seus "generosos e excelentes vinhos", "olorosos vinhos" e "olorosos licores" - como, por algum lado, se referem. O testemunho de outros vai no mesmo sentido: pela década de 1650, o que mais se produz em Portugal são muitos e excelentes vinhos (Sanson, 1698: 20-21).

Atente-se agora para o Douro, quer no seu núcleo central - Lamego-Vila Real - quer nos territórios confinantes. Aqui de anotar também os muitos e excelentes vinhos. Por várias localidades implantadas, afinal, nas duas margens. Tomé Pinheiro da Veiga, quando entrou por ali, vindo das Castelas, anotou um agradável contraste com as terras de alémfronteira: as de cá carregadas de vinhos (Fatigimia, 1988).

Importa chamar a atenção do facto e reforçar a ideia de que é nesse período que se verifica a grande expansão dos vinhedos em Portugal e, mais que isso, que se constrói e solidifica a geografia vinhateira nacional tendo sempre em atenção o que se afirmou desde o início: que a vinha anda em cultivo por todo o lado. Não importa aqui juntar mais dados sobre esta questão ou resumir os que já adiantámos (e chamando a atenção para outras particularidades em torno dos vinhos de Cima Douro que, naturalmente, aqui se passam).

Deixados os vinhos do Sul, atentemos o que se passa no Norte sobre os que, ao presente, temos mais dados. De modo sucinto pode afirmar-se, na verdade, o aparecimento de duas principais áreas vinícolas que se definem com clareza nesta primeira metade do Século XVII, constituindo autênticas zonas de produção que - se nos permitisse algum exagero - mas na lógica do que aqui se enuncia- as poderemos denominar já de autênticas "zonas demarcadas".

Assim, com a área "naturalmente demarcada "dos de Monção" e depois a área "naturalmente demarcada" e, sem dúvida, de maior expressão e maior nome - dos vinhos de Cima Douro.

Tanto para área dos de Monção como dos de Cima Douro, os testemunhos ficaram plasmados nas confissões prestadas pelos povos das duas regiões, coincidentes com os tempos que imediatamente se seguiram a 1640. Uns a propósito das devastações e perturbações provocadas pela guerra, outros, por graves conflitos de interesses provocados pelos pedidos e derramas, pedidos de dinheiros ao conjunto do Reino. Nos dois casos o testemunhado reporta-se a um processo que se tinha realizado, desenvolvido e consolidado nos tempos anteriores, dado o espaço requerido para uma boa produção entre o plantio e os resultados palpáveis desse mesmo plantio. (É verdade que já vimos, em tempos recentes, uma plantação efectuada dar origem ano seguinte - não posso afirmar agora se até no mesmo ano - a uma marca de vinhos devidamente engarrafada, selada, e recomendada e posta no mercado! Mas isso são milagres de hoje que a natureza de então ainda não prodigalizava). Ora, um conveniente tempo de "pousio" ou de "improdução" ou muito baixa produção, atira-nos inevitavelmente, para uma realidade construída nos tempos anteriores coincidente, pois, com a administração filipina. 
I) A área dos vinhos de Monção.

"Valde, (summa) laudantur vina quibus (sunt) ex oppido Monsano, juxta Gallaecus". (Apud Vasconcellii. c. 1621. Isto é, se bem traduzo: "são de particular importância e apreço os vinhos que se colhem nas redondezas de Monção - próximo da Galiza”).

Estamos perante vinhos de superior qualidade com presença no mercado interno e de exportação para o exterior. Tinha-se naturalmente construído essa realidade nos tempos anteriores, tendo constituído a primeira metade do Século XVI, numa etapa muito importante para a expansão destes vinhos tanto nos mercados internos como externos. Eram vinhos de superior qualidade e desde aquele século XVI que são selectivamente separados dos restantes do Entre Douro e Minho com a bem significativa designação de "Vinhos maduros" de Monção.

Ora, os povos deste distrito vinhateiro acabam, nos tempos imediatamente sequentes à Restauração, de nos dar conta de duas importantes realidades.

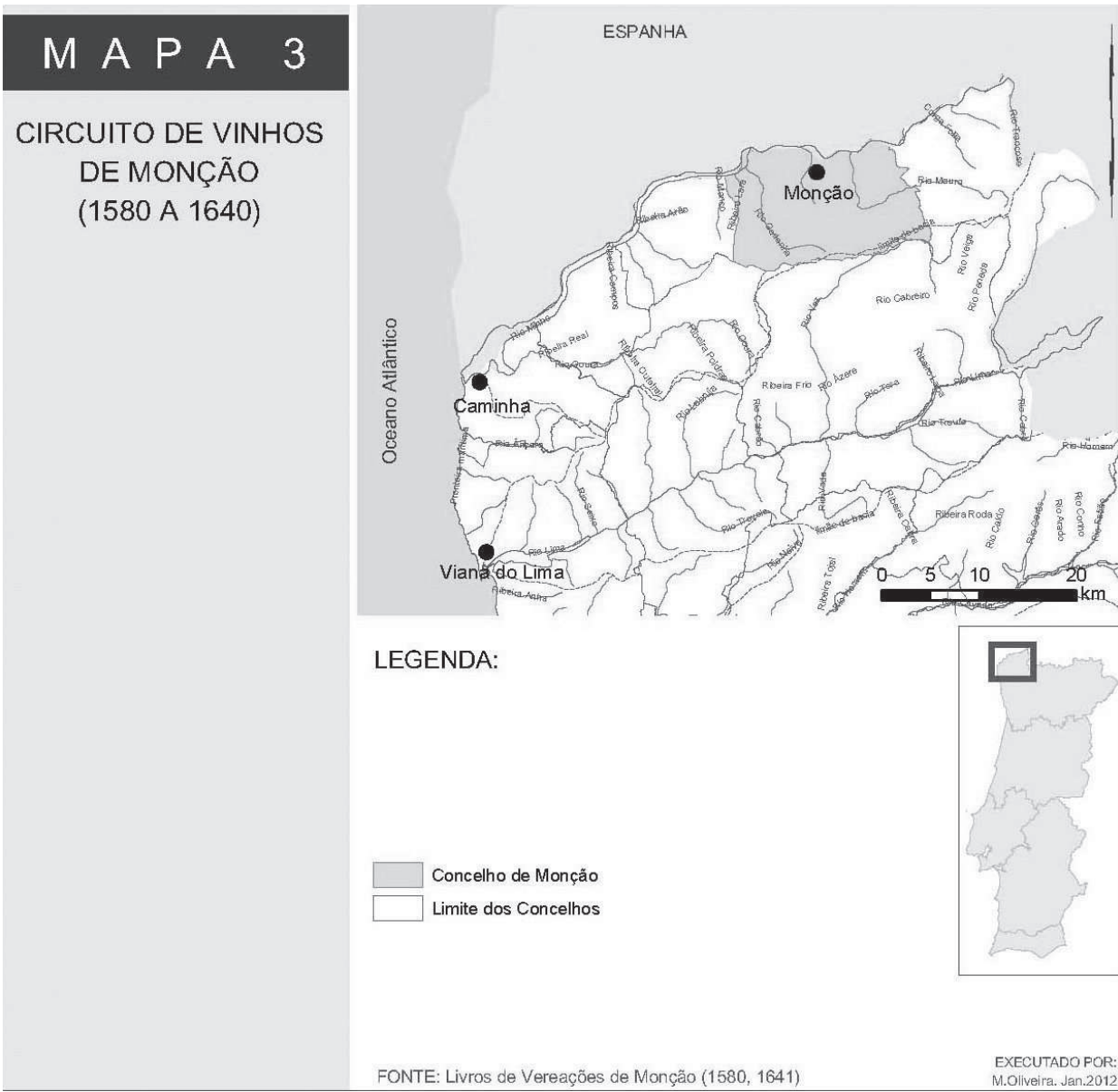


A saber:

a) que os vinhedos deste distrito - isto é, Monção e seu Termo - haviam tomado uma expansão importante e significativa. Estavam indubitavelmente em alta também pelos anos Vinte de Seiscentos. Anos depois, suas principais queixas ao monarca expressas em Cortes até meados do Século XVII, são acerca dos malefícios da guerra sobre os seus vinhedos. A constatação é clara e importante: as suas lavouras tinham-se essencialmente concentrado em torno vinhas e dos tratos com os vinhos. Viriam mesmo a confessar que era esta a actividade de que principalmente viviam, sem terem outras culturas que os sustentassem. Nós entendemos que não ainda em sistema de monocultura. É evidente, porém, que estaremos perante um fenómeno de cultura extensiva (Sobre que tipo de propriedades?)

Logo em 1641 referem que não têm outros tratos de que viver senão produzir, comprar e revender vinhos. E, na verdade, os viajantes desta altura, traçando a geografia da terra confirmam esta principal produção: "grande quantidade de olorosos vinhos que se exportam para todo o lado".

Em 1642 logo se lamentam de muitas terras abandonadas por causa das hostilidades e das imediatas perdas verificadas nas lavouras de vinhos. Por 1646, agravam-se as queixas com a indicação de despovoamento e de emigração para o exterior, em particular, para as terras do Brasil. Monção queixa-se, por então, de perdas muito graves nas novidades dos vinhedos pelos embargos e das levas e alojamento de soldados. Solicitam, então, ao Monarca que, ao menos, deixe circular os vinhos sem encargos para minorar tanta perda no seu viver.

Mas é com as Cortes de 1653 que vemos e podemos apreciar o volume dos estragos provocados no sector: destruições e abandono da cultura que se apercebe ser a principal ocupação e recurso agrícola dos povos destes distritos, em particular no de Monção. Naquele ano de 1653 queixam-se das consequências de 13 anos de guerra continuada sobre uma cultura que tende quase a surgir numa extensão de monocultura! Prejuízos particularmente graves "por ser a agricultura principal, de que resultavam constantes desordens e até mortes". As dificuldades ainda estavam presentes pelos anos de 1661-62, levando a Câmara de Viana a pedir socorro de pão ao Porto pelas devastações provocadas pelo inimigo. Mas não temos grande dúvida também, que por se terem encurtado, talvez em demasia, as terras de pão em favor dos vinhedos.

b) Já desde antes, mas também em paralelo com esta realidade, e que depois se repetirá a tempos pelos tempos posteriores, é a outra componente importante que aqui queremos em particular focar e sublinhar: a presença de uma área de produção, naturalmente demarcada em torno destes vinhedos, secundada defendida e protegida por medidas e posturas municipais. Na verdade, e porque estes vinhos eram de excelente qualidade e sofriam particular saída e exportação, assegurando vendas e mercados vantajosos, os povos de outros distritos limítrofes, tentam meter neste as suas produções, querendo ou pretendendo passar os seus vinhos como sendo vinhos de Monção. Na realidade, a constatação pelos vizinhos de uma área de excelência, caucionada, aliás e também, pelas acções administrativas da edilidade e que os naturais querem, por 
todos os meios proteger e defender. A edilidade, naturalmente protagonizando os interesses vinhateiros dos seus "vizinhos", acaba por defender o seu produto, proibindo a introdução pelos termos de Monção de outros vinhos. Os intrusos reconhecendo a importância desta marca regional de origem, pretendiam pois fazê-los passar como de Monção. Diríamos hoje, que iam ai buscar o selo de garantia, como hoje se vai chancelar a muitas repartições!

Ora, isto em Monção aparece desde muito cedo. Das primeiras referências que encontro respeitam a estes tempos para os quais vimos chamando a atenção são coincidentes com a administração filipina. É até provável que se tenham imposto estas determinações desde o início de Seiscentos. Todavia, as de 1635 (primeiras existentes) são liminares a este respeito: "acordaram que porquanto havia pessoas que por interessarem e mercanciarem mandaram ou mandavam) vir de fora deste Termo e os vendiam pelos mesmos preços que os do terra, sendo os ditos vinhos muito inferiores - no que recebe este povo muito prejuízo. Assim acordaram que nenhuma pessoa de qualquer calidade que seja possa vender vinho de fora (como sendo de Monção)... sob prisão e multa".

As determinações repetiram-se pelos tempos posteriores. Assim em 1669 proibindo novamente esse circuito de vinhos que iam ali buscar a chancela de Monção, procurando essa marca de origem. Entre outros, o dos Arcos estavam praticando isso com manifesto prejuízo dos vinhateiros e vinhos de Monção misturando os seus com estes "para depois os irem vender fora deste termo dizendo que é daqui"! Os responsáveis várias vezes legislaram no sentido de não haver confusão com outros vinhos da região que - parece - faziam trânsito por aqui distinguindo-os claramente e fixando-lhes preços diferentes, e sempre abaixo destes da região "demarcada do Monção": Assim, entre outros, os de S. João de Longos, Bela, Barbeita e Merufe como também de Pias, Valadares e Arcos.

Era já defesa de marca e de preços. O permitir-se igualdade de preços aos que não eram de Monção "era irracional por ser o que se lavra por este Termo de generosidade e capitulação maior". Urgia por isso protegê-lo. E saía muito para fora como de Monção quando na realidade o não era, o que representava manifesto prejuízo dos do Termo. Era, pois, necessário acabar com esta confusão distinguindo também nos preços o vinho do Termo face aos vinhos de fora do Termo. E assim se "legislou", várias vezes pelos tempos subsequentes. - Mais: ordena-se o registo obrigatório na Câmara do vinho de fora que vem a vender para consumo da vila. Tudo, naturalmente, por efeitos de controle e defesa de "marca".

Estamos, segundo penso, perante uma área de produção naturalmente demarcada e circunscrita, defendida e caucionada por medidas administrativas ainda que de âmbito estritamente local, isto é, sem a intervenção e a polícia do governo central. Todavia, o que também é relevante, o Poder Central não contesta as medidas administrativas tomadas por este poder local. Antes as releva, pois as medidas eram para respeitar por todos produtores e sacadores, de qualquer parte que fossem, aplicando coimas e penalidades aos infractores. Duas realidades e testemunhos históricos importantes - me parece. 
II) Venhamos ao Porto, isto é, aos vinhos de Cima Douro.

Estamos aqui perante realidades únicas muito importantes, tanto do ponto de vista de formação natural destas áreas como do seu controle administrativo. Também em síntese e a saber, juntando, porém, mais dados:

Em primeiro lugar a construção de uma cidade vinhateira - o Porto - com terrenos vinhateiros que não são do seu alforge. Cremos até tratar-se praticamente de um caso único. Até uma realidade muito precoce. O Porto, consegue apoderar-se economicamente e administrativamente - se assim poderemos falar - de um território e de uma produção que não é sua, sobrepondo-se em torno deste produto inclusivé aos próprios distritos ou municípios vinhateiros do interior do Vale, em áreas consideravelmente afastados das suas portas. Uma realidade tão grande e tão precoce e tão forte que nem o próprio monarca conseguia, facilmente, ultrapassar. Se queria encher o seu pichel, por seus feitores e contratadores, e várias vezes o tentou, tinha que se munir das respectivas licenças e alvarás municipais! Antes de levantar o seu copo tinha que reverenciar o copeiro-mor do Douro isto é.o Porto! Quando não o fez, e isso aconteceu também várias vezes, viu por parte da cidade do Porto, os seus feitores e as suas "sedes" embargadas!

III) Como para Monção, retenhamos idêntica ordem de testemunhos:

As guerras e conflitos da Restauração (1641-1668) não tiveram directa repercussão nas áreas do interior do Douro. Todavia, foram indiretamente afectadas e seriamente. Os reflexos indirectos foram muito importantes. Os impostos de guerra votados em Cortes foram pesados. Peripécias graves quanto à derrama como à cobrança das Décimas para esse auxílio levaram a um grave conflito entre o centro mercantil que era a cidade do Porto, e as zonas do vale interior produtoras dos vinhos, ao que se adivinha já, em escala extensiva tanto na lavra como nos respectivos tratos. A escápula de saída era a cidade do Porto. Surgiria o que então designamos, a primeira grande questão vinícola do Douro liminarmente consubstanciada entre os interesses urbanos mercantis da cidade e os interesses rurais e fundiários das populações do Cima Douro (ou de radicados no Porto, mas com propriedades vinhateiras no Vale). Conflito grave, com contornos de claros afrontamentos que só a directa intervenção do Monarca, com muito custo e com cedências da sua parte, se conseguiram ultrapassar.

Como já mais desenvolvidamente disso nos ocupámos, digamos em síntese, que as dificuldades começam logo em 1642 agravam-se em 1645 e atingem o auge da 1647-48.

Venhamos ao que aqui interessa: Os povos do interior do vale acabam por queixarse da irregularidade e ilícito do rateio que a Câmara pretendia impor. Ante orelhas surdas, levam os protestos directamente ao monarca. A generalidade das populações de Cima Douro, donde vinham os vinhos á cidade confessam, então, durante este percurso e em momentos vários, não ter mais do que viver do que da lavoura e trato dos vinhos.

As imposições do Porto procurando alijar de si os encargos da Décima para sobre as populações vinhateiras, levantaram todas estas populações do Cima Douro. Dizem: "tantos povos que não tem outras fazendas nem trato senão de vinhos". E no decurso 
destas queixas e exposições citam-se várias terras por onde isso, em particular, acontecia: "Lamego, Vila Real, Mesão Frio, Valdigem Penaguião, "a par de muitos outros mais lugares de Cima Douro, donde vem o vinho a essa cidade do Porto". Outros como os de "Chaves e Chaves pera baixo", como os da Régua, Pinhão "e outros". No global e no grosso, "as comarcas de Lamego e de Vila Real" que - diz-se - são as populações lugares mais atingidos e afectados. Confessam que não têm outras culturas de que vivam. Estamos aqui, pois, perante uma notável expansão desta cultura naturalmente criada e consolidada também nos tempos anteriores. Estaremos, como já sublinhámos, numa dimensão não propriamente de monocultura mas perante uma inegável extensão das culturas, como sucedia também por Monção - como referimos. Áreas ou um circuito de terras vinhateiras implantadas nas duas margens do Douro. Uma produção em grande que atingindo máximos históricos que por muito tempo não foram ultrapassados.

Esta ocupação extensiva das terras e este volume de produção e de trato está confirmado no Porto pela década de vinte altura em que, aliás, parece terem-se atingido os melhores volumes de produção e de consequente trato na cidade do Porto.

A extensão destes vinhedos é um facto importante desta economia agrícola (com tudo o que ele implica de enchimento económico e demográfico destas terras). Por alturas de 1640, estava, de facto já demarcada (naturalmente demarcada) esta região vinícola, sendo, constituída pelas áreas do vale que vão até a João da Pesqueira, com dois núcleos centrados em torno das Terras de Lamego na margem Sul do Douro, e das de Vila Real na margem Norte. Entre elas ficaram expressamente referidas e documentadas as terras de Mesão Frio, Santa Marta de Penaguião, Valdigem, com também as de Chaves "e Chaves para baixo" até ao Douro. Em terras das duas margens do Douro. (NB: a partir destas referência e de outras terras que se coligem pelas actas das vereações deste período, fizemos a primeira cartografia desta região precocemente demarcada tomando por base os limites dos actuais concelhos em que geograficamente caíam (e caem essas terras). Mas a expansão dos vinhedos não se estava verificando apenas aqui. Espaços também no Douro Superior, embora o acesso aos mercados fosse efectivamente, moroso, difícil e muito mais caro. O projecto de navegabilidade do Douro desta mesma altura (década de Vinte) não pode ser estranho a tudo isto. Notável expansão da vinha, importante trato mercantil com estes vinhos (Oliveira,1996).

É, de facto, uma das realidades que julgamos das mais importantes para tempos que até recentemente se julgavam de crise generalizada e de abatimento (disso se culpabilizando, aliás, a administração filipina).

A alastramento da cultura da vinha e dos interesses criados a juzante ou a montante, é uma das realidades mais importantes deste fenómeno.

A intervenção do monarca posicionando-se ao lado destas populações atesta, sem dúvida, da veracidade das afirmações e das queixas efectivamente verdadeiras, conforme apuraram os seus agentes e informadores que disso tiraram devassa. Reconhecia-se o inconveniente ou perigosidade de o Porto agir a seu belo prazer sobre estas mesmas populações e esta mesma realidade campesina e agrícola das terras do circuito vinhateiro do interior do vale. Nos episódios finais, o sector dos tratos e do vinho na cidade, 
"acordaram-se", de certo modo, com as queixas dos produtores do circuito vinhateiro. Mas o que mais importa aqui chamar a atenção é o significado desta contenda em torno do postulado aqui enunciado: a realidade de um circuito bem definido no interior do Vale, nas chamadas terras de Cima Douro, de uma e outra banda do rio.

IV) Esta demarcação natural, acha-se confirmada aqui por outros testemunhos importantes, que podem e devem ser chamados, ou também invocados, a respeito de regulamentações quer da lavra, quer dos tratos com estes vinhos.

Considere-se, assim, a impossibilidade de meter ou vender vinhos no Porto aos que se apresentavam com o privilégio dos cutelos (isto é, vinhos de lavra própria) sem fazer prova documental de suas vinhas ou terras. Para além do mais, há outro claro objectivo: o de evitar abusos e a introdução de vinhos de outra proveniência, passando-os como próprios, ou daquela origem "demarcada". Ora, tal obriga, levaria à construção, também, de uma realidade que é também de sublinhar: uma precoce regulamentação e registo das terras ou áreas de cultura e lavra. Na prática, o levantamento dos primeiros cadastros vinhateiros dessas terras. Só poderiam ser aqui vendidos e transaccionados os que fossem provenientes das áreas "registadas", provadas como de terras próprias (pertencentes àquele circuito).

O primeiro destes cadastros nas vinhas de Cima Douro aparece-nos já na sequência de alguns conflitos em 1613 e por abusos que se registavam com a introdução de vinhos de outras proveniências. Medidas depois repetidas, por várias vezes. Assim, em 1629, 1642-43; 1646, 1658, 1672, 1682. As determinações deste ano voltam a ser explícitas: só poderão vender os lavradores (ou comerciantes) "que mostrem primeiro certidões e documentos jurídicos e autênticos por onde consta a quantia de pipas que no próprio ano tem de lavra, com a identificação das respectivas terras". Só desses vinhos se poderiam fazer vendas por miúdo ou atacado.

Vemos pela documentação que a proveniência desses vinhos e a obrigatoriedade do registo fundiário respeitava aos que se faziam passar e vender, "chancelados" como de Cima Douro. Vejamos um testemunho: Acabem-se os cutelos "por q não resulta deles senão dano do mesmo povo, porque à sombra dos de lavra própria vendem outros a sombra deles que lá compram em sima douro e, como poderosos e ricos, não obedecem a ás posturas (e determinações) da Câmara nem às justiças de S. Majestade”.

V) Esta precoce regulamentação, foi no sentido de evitar a introdução de vinhos de outra proveniência nestes distritos vinhateiros de Cima Douro, donde vinham ao Porto (e a outros destinos) porque naturalmente tinham mais procura. Mercados mais segurados, naturalmente que pela sua reconhecida qualidade, cuja genuidade era necessário manter e preservar. E estas determinações saem novamente da Cidade do Porto, donde era proveniente o grosso dos mercadores, (e importantes lavradores) mas pressionados também pelos que lavravam e viviam essencialmente, dos vinhos naqueles distritos vinhateiros.

O resultado foi uma a realidade precoce de uma verdadeira demarcação. Demarcação "natural” em primeiro lugar; mas também uma demarcação administrativa, tenha 
sido ela, embora, de carácter localista. Construção pressionada pelas áreas de produção e dos mercadores "especializados" com estes vinhos, e determinada ou consagrada, mais uma vez, pela Cidade do Porto. Toda a aristocracia portuense, (por 1620-30) era já uma aristocracia vinhateira, isto é, todos com terras de vinho no interior do vale.

Ora, isto também acontece precocemente e coincide com estes conflitos graves que se saldaram em problemas graves logo desde os inícios do Seiscentos como se verificou com a greve à venda dos vinhos. Tudo isto, naturalmente porque haveria já interesses de monta, grande cultura e grande trato com estes vinhos. Não admira, por isso, que as áreas limítrofes estivessem introduzindo por ali os seus vinhos, fazendo-os depois passar como do de Cima Douro, com manifesto prejuízo das lavouras daqueles distritos vinhateiros.

Tudo isto se estava verificando desde a primeira metade do século em que crescem as lavouras e tratos (e se lhes procurava até a reserva de mercados exteriores como se depreende das queixas que fazem ao monarca contra outros vinhos como o fizeram em 1619).

Sabemos que pelos anos sessenta, houve que acautelar interesses, defendendo (ou continuando a defender) o produto de origem. Surgem, por isso novas recomendações e proibições para que os povos confinantes não introduzam aqui os seus vinhos, fazendo-os passar como sendo de Cima Douro. (NB: andavam então por lá os da Feira, Ovar, Aveiro e Coimbra. Mas não só. Há mais intrusos englobados na referência genérica de "outros lugares" que estavam praticando o mesmo). Ora, é isso em manifesto prejuízo deste "distrito" vinhateiro em particular de Vila Real e Lamego "que são os que vivem de seus vinhos e não outros".

Finalmente e por outro lado, a ida dos mercadores de vinhos, (fossem nacionais fossem estrangeiros) a este espaço vinhateiro para efectuarem suas compras, foi interdita sem a passagem de licenças da Câmara, para o efeito. Vários objectivos se visavam com isso, mas é manifesto, mais uma vez, a reserva e o controle sobre a área produtora, num cada vez mais definido espaço vinhateiro de reserva de que o Porto não abdicava, ou que sucessivamente reforçava.

\section{CONCLUINDO:}

Há, com efeito, realidades fácticas, construídas em particular e torno destas duas áreas que acabámos de referir - Monção e Douro, e nesta dupla dimensão: áreas vinhateiras naturalmente construídas, histórica e fisicamente visíveis, administrativamente consagradas e definidas, ainda que tão só pelas determinações do poder local, mas que eram para respeitar e que se faziam respeitar. Realidades irrelevantes e sem significado para a definição de áreas demarcadas? Só as emanadas do Poder central são determinantes para constatarmos esta realidade no tecido vinícola nacional? Formalmente sim. No restante, discutível.

Determinações de meados do Seculo XVIII precoces e pioneiras mesmo no quadro europeu dimanadas e caucionadas pelo Poder Central, são o fruto inegável de todo este 
talhamento natural anterior e da defesa proseguida pelo centro local controlador - igualmente precoce e pioneiro - que levariam a riscar, com precisão, nos terrenos do Vale interior o pequeno mas precioso e louvado reino de Baco, depois denodadamente mantido, por ocasiões alargado, e sempre reforçado.

Para os e Monção, muito mais tardiamente apenas reconhecidos, quando englobados na primeira demarcação do Verdes, mas deles distintos e bem apartados desde séculos anteriores, na genérica designação de "vinhos maduros de Monção" - como os apelidavam os Bentos de Tibães. Frades, sempre excelentes autoridades nestes assuntos!...

\section{BIBLIOGRAFIA}

Barros, João de (1919): Geografia d'entre Douro e Minho e Trás os Montes. Ed. João Grave, Porto, Biblioteca Pública Municipal do Porto.

Faria, Manuel Severim de (1974): Viagens em Portugal, Ed.de J. V. Serrão, Lisboa, Academia Portuguesa de História.

Farinelli, Arturo (1920): Viajes por España Portugal desde la Edad Media hasta el Siglo XX, Madrid, Centro de Estudios Históricos.

Garcia,MercadalJ. (1952): Viajes de Extranjeros por España y Portugal, Madrid, Aguilar. Gomes, José Garção (1969): “Monção e seu Alfoz”, Arquivo do Alto Minho, Viana do Castelo, $17^{\circ}$ vol.

Guerra, Luís Figueiredo da (1902): Jornal Hortícola Agrícola, Porto.

Leão,Duarte Nunez de (1785): Descripção do reino de Portugal, Lisboa, Na Of. De SimaoThaddeo Ferreira.

Lisk,Javier de (1878): Viaje de Jacobo de Sobieski, Madrid, Col. Javier de Lisk.

Magalhães, Joaquim Romero de (1990):O Algarve Económico - 1600-1773, Lisboa.

Oliveira, Aurélio de (1984): Os Povos da Ribeira Minho em Cortes - 1641-1653, Caminha.

Oliveira, Aurélio de e Sanz, A. Garcia (1989): “Economias peninsulares no século XVII”, Penélope, Lisboa.

Oliveira, Aurélio de (1996): Os vinhos no Porto. Política e administração municipais. 1600-1700, Porto, FLUP.

Oliveira, Aurélio de (1996): Vinho e transportes no Douro (1450-1700), Gaia.

Oliveira, Aurélio de (2004): Mestre Gil, Garcia e Miranda com os vinhos em bolanda, Porto, GEHVID/Universidade do Porto.

Oliveira, Aurélio de (2006): Monção um centro vinhateiro bloqueado (1500-1822), Funchal.

Oliveira, Aurélio de (2006): Os Vinhos em Portugal (1300-1820).Um sector de sucesso na agricultura bloqueada do Antigo Regime, Talca.

Oliveira, Aurélio de (2007): No País dos Verdes - Trabalho, tradição e diversão, Porto.

Oliveira, Aurélio de (2011): Auto do Vinho, Viana do Castelo, C. M.de Viana do Castelo. 
Oliveira, Eduardo Freire (1911): Elementos para a História do Município de Lisboa, Lisboa.

Labrousse, Ernest (1944): La Crise de l'économie française à la fin de l'Ancien Régime et au début de la Révolution, Paris, Presses Universitaires de France.

Rui, Fernandes (1926): "Descripçam do Terreno em roda da cidade de Lamego duas Legoas - 1531-1532”, en Collecção de Ineditos de Historia Portugueza, T. V. Lisboa.

Sanson, Nicolas (1698): Atlas Portatifet Nouveaudu Voyageur pour le Royaume d'Espagne, Amsterdam, Chez Pierre Mortier.

Silva, Francisco Ribeiro da (1988): O Porto e seu Termo (1580-1640) - Os Homens, as Instituições e o Poder, Porto, C.M. Porto, 2 Vols.

Silva, Luiz Augusto Rebelo da (1867): História de Portugal nos Séculos XVII e XVIII, Lisboa, 5 Vols.

Vasconcellii, Antonius (1793): Anacephaleoses et Regni Lusitano Descriptio (1621), Conimbrice.

Veiga, Tomé Pinheiro da (1988): Fastigimia, Lisboa, INCM.

Vilar, Pierre (1962): La Catalogne dans l'Espagne Moderne, Paris.

\section{Arquivos (Portugal):}

Arquivo Municipal de Monção - Liv. de Vereações de Monção. (1600-1700. Hiatos).

Arquivo Municipal de Ponte de Lima - Liv. Vereações de Ponte do Lima (1600-1700. Hiatos).

Arquivo Municipal do Porto - Liv. de Vereações do Porto. 1635-1700.

Arquivo Nacional da Torre do Tombo - Gavetas (As) da Torre do Tombo. IV. Lisboa. 1964. 